\title{
Pengujian Asosiasi Tipe Wilayah dengan Kualitas Angkatan Kerja yang Bekerja di Provinsi Bengkulu
}

\author{
REY RONALD PURBA \\ Statistisi Ahli Pertama. Badan Pusat Statistik Kabupaten Bengkulu Utara \\ email : reybps@gmail.com
}

\begin{abstract}
ABSTRAK
Peningkatan kesejahteraan masyarakat merupakan salah satu program prioritas pemerintah. Salah satu tolak ukur untuk melihatnya adalah tingkat kemiskinan disuatu daerah. Provinsi Bengkulu sebagai salah satu provinsi dengan tingkat kemiskinan di Indonesia harus dapat menanggulangi permasalahan tersebut. Ketenagakerjaan dianggap merupakan salah satu cara untuk mengentaskan kemiskinan. Untuk melihat apakah kebijakan yang diambil pemerintah sudah tepat dalam meningkatkan kualitas dan pemerataan penyerapan tenaga kerja, perlu dilihat apakah ada hubungan (asosiasi) antara tipe wilayah (perdesaan dan perkotaan) dengan kualitas angkatan kerja (terdidik dan tidak terdidik) dari penduduk yang bekerja di Provinsi Bengkulu. Menggunakan Uji Beda Peluang, Uji Resiko Relatif, Uji Odds Ratio dan Uji Independensi (Chi Square) didapat bahwa memang terdapat hubungan (asosiasi) dari kedua variabel tersebut.
\end{abstract}

Kata Kunci: Karakteristik Wilayah, Kualitas angkatan kerja,, Uji Statistik.

\section{PENDAHULUAN}

Meningkatkan kualitas hidup manusia dan masyarakat Indonesia merupakan satu dari sembilan agenda prioritas (NAWACITA) yang digagas pemerintahan Presiden Joko Widodo. Peningkatan taraf kesejahteraan masyarakat Indonesia memang sudah seharusnya dinikmati dalam alam kemerdekaan yang sudah berlangsung lebih dari setengah abad. Salah satu tolak ukur keberhasilan program tersebut adalah menurunnya tingkat kemiskinan.

Pada dasarnya kemiskinan menurut Bappenas merupakan suatu kondisi dimana seseorang atau sekelompok orang, laki-laki dan perempuan, tidak mampu memenuhi hak-hak dasarnya untuk mempertahankan dan mengembangkan kehidupan yang bermatabat. Hak-hak dasar tersebut antara lain terpenuhinya kebutuhan pangan, kesehatan, pendidikan, pekerjaan, perumahan, air bersih, pertanahan, sumber daya alam dan lingkungan hidup, rasa aman dari perlakuan atau ancaman tindak kekerasan dan hak untuk berpartisipasi dalam kegiatan sosial-politik, baik bagi laki-laki maupun perempuan. Dalam pengukuran tingkat kemiskinan BPS menggunakan pendekatan pemenuhan kebutuhan dasar. Dengan pendekatan ini, kemiskinan dilihat sebagai suatu bentuk ketidakmampuan dari sisi ekonomi dalam memenuhi kebutuhan dasar makanan dan bukan makanan yang diukur dari sisi pengeluaran. Pengeluaran yang dimaksud adalah pengeluaran untuk memenuhi kebutuhan makanan dan non makanan yang dikonversikan kedalam suatu batas yang lebih dikenal sebagai garis kemiskinan. Penduduk yang memiliki rata-rata pengeluaran perkapita per bulan dibawah garis kemiskinan maka penduduk tersebut masuk dalam kategori miskin.

Provinsi Bengkulu merupakan provinsi dengan persentase penduduk miskin paling tinggi di pulau sumatera. Persentasenya mencapai nilai 17,88 persen pada tahun 2015 (BPS, 2016). Bahkan dengan nilai tersebut menempatkan Provinsi Bengkulu di urutan ke-6 dari 34 provinsi sebagai provinsi dengan persentase penduduk miskin tertinggi di Indonesia.

Penyerapan tenaga kerja yang merata di wilayah perkotaan maupun perdesaan merupakan suatu keharusan untuk mengentaskan kemiskinan. Namun pada kondisi Agustus 2015 di Provinsi Bengkulu untuk wilayah perkotaan Tingkat Partisipasi Angkatan Kerja (TPAK) mencapai 66,76 persen dengan Tingkat Pengangguran Terbuka (TPT) sebesar 6,41 persen. 


\section{Rey Ronald Purba}

Untuk wilayah pedesaan, nilai TPAK sebesar 72,55 persen dengan TPT sebesar 4,24 persen. Fakta tersebut menyatakan bahwa terdapat ketimpangan antara wilayah perkotaan dan perdesaan dalam hal penyerapan tenaga kerja. Oleh karenanya agar meningkatkan peluang seseorang untuk bekerja salah satunya dengan meningkatkan kualitasnya.

Menurut teori Human Capital, angkatan kerja yang lebih ahli dan terdidik akan lebih mampu dan mempunyai kesempatan yang lebih besar untuk mengisi lapangan pekerjaan. Oleh karenanya pemerintah berupaya untuk meningkatkan kualitas sumber daya manusia salah satunya dari sisi pendidikan. Program Kartu Indonesia Pintar yang dikeluarkan pemerintah bertujuan untuk menjamin dan memastikan agar seluruh anak usia sekolah dari keluarga kurang mampu dapat menyelesaikan pendidikannya hingga sekolah menengah.

Teori tersebut sejalan dengan data yang dirilis BPS Provinsi Bengkulu, yaitu mereka yang bekerja di perkotaan sebagian besar merupakan pekerja terdidik atau mencapai 66 persen. Namun ada fakta sebaliknya, yaitu di perdesaan sekitar 70 persen penduduk yang bekerja merupakan pekerja tidak terdidik. Hal ini juga diperkuat oleh hasil penelitian Aprianto dan Khairrunnisa (2013). Mereka melakukan penelitian mengenai hubungan sumber daya manusia terhadap tingkat pendidikan dan pengangguran terbuka di Indonesia dari tahun 2004-2013. Mereka menyimpulkan bahwa tidak terdapat hubungan antara tingkat sumber daya manusia berdasarkan tingkat pendidikan tertinggi yang ditamatkan dengan tingkat penggangguran terbuka menurut tingkat pendidikan tertinggi yang ditamatkan.

Berdasarkan hal tersebut, pada penelitian ini, penulis mencoba untuk melihat apakah ada hubungan (asosiasi) antara tipe wilayah (perdesaan dan perkotaan) dengan kualitas angkatan kerja (terdidik dan tidak terdidik) yang bekerja di Provinsi Bengkulu. Hal ini bermanfaat untuk melihat apakah program pemerintah dalam meningkatkan kualitas mutu pendidikan penduduk sudah tepat untuk meningkatkan peluang seseorang bekerja. Dengan bekerja maka akan menambah pendapatan masyarakat dan meningkatkan kesejahteraannya, dan tujuan dari program NAWACITA dapat tercapai.

\section{METODE PENELITIAN}

Penelitian ini menggunakan data sekunder yang berasal dari Publikasi Keadaan Angkatan Kerja di Provinsi Bengkulu pada Agustus 2015 yang dikeluarkan oleh BPS Provinsi Bengkulu. Adapun metode analisis yang digunakan untuk melihat asosiasi dan mendeskriptifkannya adalah Uji Beda Peluang, Uji Resiko Relatif, Uji Odds Ratio dan Uji Independensi (Chi Square).

\section{UJI BEDA PELUANG}

Uji ini untuk memberikan indikasi ada tidaknya asosiasi antara kedua variabel. Adapun rumusnya sebagai berikut:

Beda Peluang $=\pi_{j \mid h}-\pi_{j \mid i}=\hat{\pi}_{1}-\hat{\pi}_{2}$
Dengan selang kepercayaan $=\left(\hat{\pi}_{1}-\hat{\pi}_{2}\right) \pm Z_{\alpha / 2} \sqrt{\frac{\hat{\pi}_{1}\left(1-\hat{\pi}_{1}\right)}{n_{1}}+\frac{\hat{\pi}_{2}\left(1-\hat{\pi}_{2}\right)}{n_{2}}}$

Keterangan :

$\pi_{j \mid h}=$ Nilai peluang kategori $\mathrm{j}$ pada variabel $\mathrm{Y}$ untuk kategori $\mathrm{h}$ pada variabel $\mathrm{X}$

$\pi_{j \mid i}=$ Nilai peluang kategori j pada variabel Y untuk kategori i pada variabel X

Jika selang kepercayaan mengurung nilai nol maka dianggap tidak ada asosiasi diantara dua variabel.

\section{UJI RESIKO RELATIF (RR)}

Uji ini merupakan perbandingan antara dua peluang kejadian variabel Y pada 2 kategori dari variabel X. Rumusnya sebagai berikut:

$$
R R=\frac{\pi_{j \mid h}}{\pi_{j \mid i}}
$$


Dengan selang kepercayaan $=\left[R R\left(e^{-1,96 \sqrt{v}}\right), R R\left(e^{1,96 \sqrt{v}}\right)\right] \quad$ dengan $\quad \mathrm{e}=2,7183$

$; v=\frac{\left(1-\hat{\pi}_{1}\right)}{n_{11}}+\frac{\left(1-\hat{\pi}_{2}\right)}{n_{21}}$

Jika selang kepercayaan mengurung nilai satu maka dianggap tidak ada asosiasi diantara dua variabel.

\section{UJI ODDS RATIO}

Uji Odds Ratio adalah uji perbandingan dari dua odds. Pengertian odds adalah peluang terjadinya suatu kejadian dibandingkan peluang tidak terjadinya kejadian tersebut.

Adapun rumusnya sebagai berikut:

Odds $=\theta_{i}(j, k)=\frac{\pi_{j \mid h}}{\pi_{k \mid h}}, j \neq k=1, \ldots, J ; i=1, \ldots, I$

Odds Ratio $=\theta_{h i}(j, k)=\frac{\theta_{h}(j, k)}{\theta_{i}(j, k)}$ atau $\frac{n_{11} n_{m 2}}{n_{n n} n_{m 11}}$

Dengan selang kepercayaan $\log \hat{\theta} \pm Z_{\alpha / 2} A S E(\log \hat{\theta})$, dimana

$\operatorname{ASE}(\log \hat{\theta})=\sqrt{\frac{1}{n_{11}}+\frac{1}{n_{12}}+\frac{1}{n_{21}}+\frac{1}{n_{22}}}$

Jika selang kepercayaan mengurung nilai satu maka dianggap tidak ada asosiasi diantara dua variabel.

\section{UJI INDEPENDENSI (CHI SQUARE)}

Uji ini digunakan untuk menguji dua kelompok data yang berbentuk kategorik. Pada dasarnya uji ini membandingkan perbedaan frekuensi hasil observasi dengan frekuensi yang diharapkan. Adapun rumusnya sebagai berikut:

$\lambda^{2}=\sum \frac{\left(n_{i j}-\hat{\mu}_{i j}\right)^{2}}{\hat{\mu}_{i j}}$

Dengan :

$n_{i j} \quad=$ Frekuensi hasil observasi pada variabel $\mathrm{X}$ kategori i dan variabel $\mathrm{Y}$ kategori $\mathrm{j}$

$\hat{\mu}_{i j} \quad=$ Frekuensi yang diharapkan pada variabel $\mathrm{X}$ kategori $\mathrm{i}$ dan variabel $\mathrm{Y}$ kategori $\mathrm{j}$

Kedua kelompok data dikatakan saling independen jika $\lambda^{2} \geq x_{\alpha_{i}[-1)(1-1)}^{2}$

Adapun konsep-konsep yang dipakai didalam penelitian ini adalah sebagai berikut:

- Angkatan kerja adalah penduduk usia kerja (15 tahun dan lebih) yang bekerja, atau punya pekerjaan namun sementara tidak bekerja dan pengangguran.

- Bekerja adalah kegiatan ekonomi yang dilakukan oleh seseorang dengan maksud memperoleh atau membantu memperoleh pendapatan atau keuntungan, paling sedikit 1 jam (tidak terputus) dalam seminggu yang lalu. Kegiatan tersebut termasuk pula kegiatan pekerja tak dibayar yang membantu dalam suatu usaha/kegiatan ekonomi.

- Kualitas angkatan kerja yang bekerja dibagi kedalam dua kategori, yaitu terdidik dan tidak terdidik. Yang dimaksud angkatan kerja terdidik adalah angkatan kerja yang memiliki tingkat pendidikan menengah keatas, yaitu yang mempunyai ijazah SMA, SMK maupun sederajat, serta pendidikan tinggi yang meliputi diploma ke atas. Sedangkan angkatan kerja tidak terdidik adalah angkatan kerja yang memiliki ijazah SMP kebawah, termasuk yang tidak tamat SD dan yang tidak pernah sekolah. 


\section{Rey Ronald Purba}

\section{HASIL DAN PEMBAHASAN}

Objek dalam penelitian ini adalah penduduk usia 15 tahun keatas yang bekerja di Provinsi Bengkulu. Adapun data disajikan dalam tabel kontingensi sebagai berikut:

Tabel 1. Penduduk usia 15 tahun yang bekerja berdasarkan tipe wilayah dan kualitas angkatan kerja di Provinsi Bengkulu tahun 2015 (orang)

\begin{tabular}{|l|r|r|l|}
\hline \multirow{2}{*}{ Tipe Wilayah } & \multicolumn{2}{|c|}{ Kualitas Angkatan Kerja } & \multirow{2}{*}{ Total } \\
\cline { 2 - 3 } & Tidak Terdidik & \multicolumn{1}{c|}{ Terdidik } & \multicolumn{1}{|c|}{} \\
\hline Perkotaan & 99,336 & 193,085 & 292,421 \\
\hline Pedesaan & 464,635 & 193,951 & 658,586 \\
\hline Total & 563,971 & 387,036 & 951,007 \\
\hline
\end{tabular}

Sumber : BPS, diolah

\section{UJI BEDA PELUANG}

Dengan menggunakan nilai peluang kategori tidak terdidik pada tipe wilayah perkotaan dengan nilai peluang kategori tidak terdidik pada tipe wilayah perdesaan didapat dinilai selisih sebesar $-0.3658$.

$\pi_{1 \mid 1}=$ peluang kategori tidak terdidik pada tipe wilayah perkotaan

$=99,336 / 292,421=0.339702$

$\pi_{1 \mid 2}=$ peluang kategori tidak terdidik pada tipe wilayah perdesaan

$=464,635 / 658,586=0.705504$

Beda Peluang $\quad=\pi_{1\left[1^{-}\right.} \pi_{1 \mid 2}$

$$
=0,339702-0,705504=-0.3658
$$

Selang kepercayaan $\quad=\left(\hat{\pi}_{1}-\hat{\pi}_{2}\right) \pm Z_{\alpha / 2} \sqrt{\frac{\hat{\pi}_{1}\left(1-\hat{\pi}_{1}\right)}{n_{1}}+\frac{\hat{\pi}_{2}\left(1-\hat{\pi}_{2}\right)}{n_{2}}} \quad$ dengan $\quad \hat{\pi}_{1}=0.339702$; $\widehat{\pi}_{2}=0.705504 ; n_{1}=292,421 ; n_{2}=658,586 ; \alpha=0.05$ didapat selang kepercayaan terletak antara -0.36784 dan -0.36376 .

Hal ini mengindikasikan bahwa memang terdapat asosiasi antara tipe wilayah dengan kualitas angkatan kerja yang bekerja di Provinsi Bengkulu.

\section{UJI RESIKO RELATIF}

$\mathrm{RR}=\frac{\pi_{1} \|_{1}}{\pi_{1 \| \Sigma}}=0,481503$

Nilai tersebut mengindikasikan bahwa peluang seseorang bekerja dengan kategori kualitas angkatan kerja yang tidak terdidik pada tipe wilayah perkotaan lebih kecil 48 persen dibandingkan pada tipe wilayah perdesaan.

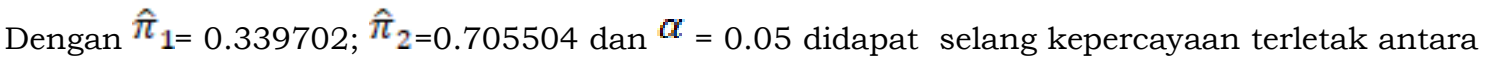
0,478963 dan 0,484056. Hal ini mengindikasikan bahwa memang terdapat asosiasi antara tipe wilayah dengan kualitas angkatan kerja yang bekerja di Provinsi Bengkulu.

\section{UJI ODDS RATIO}

$$
\begin{aligned}
& \theta_{h i}(j, k)=\frac{n_{11} \cdot n_{2 n}}{n_{12} \cdot n_{m 1}} \\
& \text { 99,336.193,951 } \\
& =\overline{193_{\imath}, 085.464,635}=0.214753
\end{aligned}
$$


Agar lebih mudah dalam interpretasikan hasilnya, maka penghitungannya dibalik.

$\theta_{i h}(j, k)=\frac{193,085,464,635}{99,336.193,951}=4.656523$

Hasil diatas mengindikasikan bahwa penduduk yang bekerja di wilayah perdesaan dengan kualitas angkatan kerja tidak terdidik cenderung 4 kali lebih mungkin dibandingkan di wilayah perkotaan.

Dengan menggunakan $\alpha=0.05$ didapat selang kepercayaan diantara 4,61 dan 4,7. Hal ini mengindikasikan bahwa memang terdapat asosiasi antara tipe wilayah dengan kualitas angkatan kerja yang bekerja di Provinsi Bengkulu.

\section{UJI INDEPENDENSI (CHI SQUARE)}

Untuk melihat apakah ada asosiasi antara tipe wilayah (perdesaan dan perkotaan) dengan kualitas angkatan kerja (tidak terdidik dan terdidik) yang bekerja di Provinsi Bengkulu perlu dilakukan suatu pengujian hipotesis. Adapun hipotesisnya adalah:

$H_{0}: \pi_{i j}=\pi_{\tilde{i}} x \pi_{\cdot j}$ (tidak ada asosiasi antara tipe wilayah dengan kualitas angkatan kerja)

$H_{i}: \pi_{i j} \neq \pi_{i} x \pi_{s i}$ (terdapat asosiasi antara tipe wilayah dengan kualitas angkatan kerja)

Statistik uji yang digunakan adalah:

$\lambda^{2}=\sum \frac{\left(n_{i j}-\hat{\mu}_{i j}\right)^{2}}{\hat{\mu}_{i j}}$
$\hat{\mu}_{i j}=\frac{n_{i} n_{\mathrm{o} j}}{n}$

Maka:

$$
\begin{aligned}
& \hat{\mu}_{11}=\frac{n_{1} n_{i 1}}{n} \\
& =\frac{292,421 * 563,971}{951,007}=173,412.99 \\
& \hat{\mu}_{22}=\frac{n_{2}, n_{22}}{n} \\
& =\frac{658,586 * 387,036}{951_{\imath} 007}=268,027.99 \\
& \lambda^{2}=\sum \frac{\left(n_{i j}-\hat{\mu}_{i j}\right)^{2}}{\hat{\mu}_{i j}} \\
& =\frac{(99,336-173,412.99)^{2}}{173,412.99}+\cdots+\frac{(193.951-268,027.99)^{2}}{268,027.99}=112,276.422
\end{aligned}
$$

Denga kriteria uji tolak $H_{0}$ jika $\lambda^{2} \geq \lambda_{\alpha ;(I-1)(J-1)}^{2}$.

Dengan $\alpha=0.05$ didapat $\lambda_{\alpha ;(I-1)(j-1)}^{2}=5,99$ yang berarti tolak $H_{0}$. Atau dengan kata lain, memang terdapat asosiasi antara tipe wilayah dengan kualitas angkatan kerja yang bekerja di Provinsi Bengkulu dengan tingkat kepercayaan 95 persen. 


\section{Rey Ronald Purba}

\section{KESIMPULAN}

Dengan menggunakan Uji Beda Peluang, Uji Resiko Relatif, Uji Odds Ratio dan Uji Independensi (Chi Square), didapat bahwa memang terdapat hubungan (asosiasi) antara tipe wilayah dengan kualitas angkatan kerja yang bekerja di Provinsi Bengkulu tahun 2015. Oleh karenanya kebijakan pemerintah dengan meningkatkan kualitas dalam bidang pendidikan guna pemerataan penyerapan tenaga kerja di daerah perkotaan maupun perdesaan dirasa sudah tepat. Tentunya tujuan akhir agar kesejahteraan masyarakat khususnya di Provinsi Bengkulu meningkat sangat diharapkan.

Fenomena bahwa penduduk yang bekerja di wilayah perdesaan dengan kualitas angkatan kerja tidak terdidik cenderung 4 kali lebih mungkin dibandingkan di wilayah perkotaan berhasil ditangkap pada penelitian ini. Kenyataan ini sebaiknya dapat dijadikan sebagai acuan untuk pengambilan kebijakan kedepan, agar dapat memaksimalkan penyerapan tenaga kerja di Provinsi Bengkulu. Selanjutnya agar kebijakan pemerintah lebih tepat sasaran, perlu diadakan penelitian lebih lanjut mengenai faktor-faktor yang mempengaruhi penyerapan tenaga kerja di wilayah perkotaan maupun perdesaan selain dari sisi pendidikan tertinggi yang ditamatkan.

\section{DAFTAR PUSTAKA}

Agresti, Alan. 2007. An Introduction to Categorical Data Analysis, Second Edition. John Wiley\&Sons Inc, USA.

Aprianto, Dharfan dan Khairrunnisa, Ulfah. 2013. Hubungan sumber Daya Manusia Terhadap Tingkat Pendidikan dan Pengangguran Terbuka di Indonesia. Proceeding PESAT, Vol 5.

Badan Pusat Statistik [BPS] Provinsi Bengkulu. 2015. Keadaan Angkatan Kerja di Provinsi Bengkulu agustus 2015. Bengkulu: Perum Percetakan Negara RI.

Badan Pusat Statistik [BPS]. 2016. Penghitungan dan Analisis Kemiskinan Makro Indonesia 2016. Jakarta: BPS.

Badan Pusat Statistik [BPS]. 2016. Data dan Informasi Kemiskinan Kabupaten/Kota Tahun 2015. Jakarta: BPS.

Octaviani, Dian. 2001. Inflasi, Pengangguran, dan Kemiskinan di Indonesia: Analisis Indeks Forrester Greer \& Horbecke. Media Ekonomi, Hal. 100- 118, Vol. 7, No. 8.

Perry GE, Arias OS, Lopez JH, Maloney WF, Serven L. 2006. Poverty Reduction and Growth: Virtuous and Vicious Circles. New York: World Bank.

Rusdarti dan Lesta. 2013. Faktor-Faktor yang Mempengaruhi Tingkat Kemiskinan di Provinsi Jawa Tengah. Jurnal Economia, Volume 9, Nomor 1.

Todaro, M.P., dan Smith, S.C. 2011. Pembangunan Ekonomi, Edisi kesebelas, Jilid I. Erlangga, Jakarta.

Yacoub, Yarlina. 2012. Pengaruh Tingkat Pengangguran Terhadap Tingkat Kemiskinan Kabupaten/Kota di Provinsi Kalimantan Barat. Jurnal EKSOS Vol 8, hal 176-185. 